\title{
Langenbeck's Archives: the international journal of the German Society of Surgery
}

\author{
Reiner Gradinger • Hartwig Bauer
}

Received: 2 March 2010 /Accepted: 2 March 2010 /Published online: 21 March 2010

(C) Springer-Verlag 2010

In 2010, the German Society of Surgery is celebrating the 150th anniversary of publishing the journal "Langenbeck's Archiv". In February 1860, Bernhard von Langenbeck, Professor of Surgery and Ophthalmology and Chairman of the Department of Surgery, Berlin, in cooperation with Th. Billroth, Zurich, and G. Gurlt, Berlin, founded the journal "Archiv für Klinische Chirurgie". In the second half of the nineteenth century, German surgeons contributed immensely to the evolution of surgical practice. In the last 150 years, major developments in surgery were published in 395 volumes of "Archiv für Klinische Chirurgie" mirroring the development of surgery in Germany and the world.

Therefore, Ernst von Bergmann, Langenbeck's successor at the University Hospital in Berlin found the perfect words to describe his predecessor as well as the journal: "He was the right man in the right place at the right time". Langenbeck's Archiv was founded at the right time. It was developed over time-150 years - by the right men.

Under the leadership of Th. Billroth, Zurich/Wien, Archiv für Klinische Chirurgie was positioned from the beginning as an international surgical journal with contributions from international surgeons: Austria and Switzerland, Sweden, Netherlands, Russia, Japan, United States, and France. Its exceptional success and continuity has been driven by the editors, many of them world-famous surgeons, opinion leaders, and outstanding researchers. Since the foundation of the German Society of Surgery, 1872, the journal reflects the evolution of surgical specialties in Germany. Ever since its

\footnotetext{
R. Gradinger

DGCH,

Munich, Germany

H. Bauer $(\triangle)$

DGCH,

Berlin, Germany

e-mail: H.Bauer@dgch.de
}

first issue results of experimental surgery have been published and still remain a main topic of the journal until now.

In the second half of the nineteenth century, the main focus of the published manuscripts had been abdominal surgery, trauma and orthopedic surgery, thyroid surgery, and urogenital surgery. Today, the major topics at the annual meeting of the German Society of Surgery and in Langenbeck's Archives of Surgery, as well, are minimal invasive surgery in various specialities. For orthopedic and trauma, reconstructive and vascular surgery and other specialized journals have sprung to existence.

Since 1998, Langenbeck's Archives has been published in English with contributions by surgeons of the German Society of Surgery and others. With the decision to change to a journal published in English Langenbeck's Archives of Surgery has grown into an international, highly ranked journal. The German Society of Surgery continues to be, since 1872, the basis for contributions of German surgeons to the journal. Along with his renowned predecessors Ferdinand Sauerbruch, K.H. Bauer, Fritz Linder, Martin Allgöwer, and Michael Trede, the current editor in chief Hans Beger strongly contributed to this achievement. Our Society wishes to acknowledge these achievements by Hans Beger, the co-editors, the editorial board, and the publishers, to name only a few and therefore we would like to express our gratitude. The success of a scientific journal could not be documented better than by its 150th anniversary, especially in a time when scientific publications disappear as fast as they appeared.

What does one ask for under these circumstances? For scientific contributions of high standards, about which one can repeat, what has been said about the eloquence of its founding father, Bernhard von Langenbeck: In seltener Weise anmutend, fesselnd und eindrucksvoll. "Strangely appealing, compelling and impressive": Langenbeck's Archives of Surgery-Ad multos annos! 